\title{
The Impact of Social Labour Plans (SLPs) on the Advancement of Local Economic Development: A Case Study of South Africa
}

\author{
Adv Bheki Khenisa \\ Municipal Manger, Steve Tshwete Local Municipality, Mpumalanga, South Africa
}

\begin{abstract}
The purpose of this survey was to theoretically appraise the impact of Social and Labor Plans (SLPs) on the advancement of local economic development with special reference to the South African situation. A desktop literature review research method was adopted by the survey to establish the role that SLPs have played in Africa as well as on the global platform. Reference was made to literature gathered on specific cases in the Republic of South Africa. The survey came up with the following findings: tendencies of undemocratic approach to development, no access to SLPs and related information, weak co-operative governance and responsibility shifting, no regional alignment of SLP initiatives, companies' relationship with traditional leaders and exclusion of communities. Therefore, based on the aforementioned findings, the survey recommended the following: making the process of requesting information from the major stakeholders more accessible to communities; ensuring clearer legislative provisions regarding transparency of SLPs; ensuring that mining laws, regulations and policy recognise and acknowledge communities as central role players; Pursuance of Bench Marks Foundation's proposal meant to address the challenges of mine-affected communities; specification of requirements for community participation in the design and amendment of SLPs; clarification on giving feedback to communities on progress made in SLPs; integrating the development of SLPs into the IDP annual review and require community participation in this process.
\end{abstract}

Keywords: Social and Labor Plans, Local Economic Development, Mineral and Petroleum Resource Development Act

DOI: $10.7176 / \mathrm{PPAR} / 10-8-07$

Publication date:August $31^{\text {st }} 2020$

\subsection{Introduction}

The mining sector in South Africa has been under siege because of many challenges ranging from uncertainty in policy and legislation, political power struggles and mine-community discontentment. In-spite of the efforts by the state to find a lasting solution to such issues, the mine-affected communities are still without tangible and meaningful benefits. This is contrary to the community and worker supposed benefits as stipulated in the Mining Charter and the Social and Labor Plan (SLP) System which contain direct obligations to contribute meaningfully to the economic and social development of mine-affected communities (Donk, Swilling, Pieterse \& Parnell, 2016). The SLP system, in particular, is supposed to ensure that mine-affected communities benefit significantly and are not left destitute and impoverished by mining activities. The assumption is that countries which boast huge reserves of mineral resources should be fortunate enough to rise in terms of development not only in their major cities but also in the local communities where mining is taking place. Thus, at both local and regional level, economic development should expectedly be an end result of mining activities. According to Eggert (2001), this trend is evident in the East Coast of the United States, Western Australia, Victoria in Australia and Johannesburg in South Africa among many others (Bank 2012).

Following the systematic marginalization of the majority of its citizens, authored by the segregatory apartheid regime policies which saw the Historically Disadvantaged South Africans (HDAs) being denied the opportunities to be custodians of means of production as well as significant participants in the mainstream of the economy, the democratic government, in 1996, enacted the Mineral and Petroleum Resource Development Act 28 of 2002(MPRDA). The principle mandate of the MPRDA is to enhance the socio-economic welfare of all South Africans through employment creation while at the same time ensuring that companies holding mining rights give back and invest towards socio-economic development in their operating areas. Thus, in order to accomplish this objective of the MPRDA, the Social and Labor Plans (SPL) regime was launched (Kaznacheev, 2013).

Nevertheless, previous researches have established that the SLP design and implementation lack the coherence that promotes significant and sustainable social and economic advancement of local communities. Thus, SLPs have failed to come up with a roadmap that will help accomplish their intended objectives of promoting the social and economic welfare of mine-affected communities. This survey will give a breakdown of the challenges or flaws that have caused or inhibited SLPs to be effective in their delivery as well as recommending both immediate and longer term measures that can be put in place to ensure they achieve the intended goals and objectives. While the immediate recommendations are meant to be implemented instantly given the fact that they operate within the current legal framework, the longer term recommendations are designed to make reforms in SLPs whose aim is to bring about a paradigm shift in power dynamics as well as the legal framework. 
Reference will be made to a research carried out by The Centre for Applied Legal Studies (CALS) into the SLP system. Its findings proved beyond any doubt that the SLP system has many flaws both in its design and implementation, (CALS, 2018).

\subsection{Problem Statement}

Huge mineral deposits in any given country place it in an ideal position for vibrant economic development both at local and national level. However, evidence from various international cases, more so in developing countries, has compelled scholars to report a negative correlation between economic development and the exploration of natural resources (Auty, Sachs and Warner, 1995). Harvey (2014), in support of the above assertion, posits that mining has instead created enclave economies where neither the country nor near-mine communities benefit in terms of its potential contribution to sustainable socio-economic development. Mining towns are associated with underdevelopment and the subsequent socio-economic challenges of poverty and unemployment. It has been discovered that many households depend on social grants as their immediate and reliable source of income and because of unemployment; the majority of young people in the mining towns are not going to school (MGDS, 2014). To this end, this study seeks to evaluate the impact of SPL in advancing the wellbeing of communities in mine affected communities.

\subsection{Research Objective(s)}

The primary objective for this study is enlisted as follows:

- To appraise impact of SLPs on the advancement of local economic development in South Africa. Secondary objectives:

- To identify the immediate and long term measures that can be taken to address the current flaws in the SPL legal framework with South Africa.

- To explore the sustainability of the local economic development initiatives introduced by the South African mining houses.

\subsection{Research Questions}

The research endeavors to answer the primary question, which was informed by the purpose statement and mainly seeks to establish the role played by the SLPs in the economic development of the local communities.

Primary question:

- What is the impact of SLPs on the advancement of local economic development in South Africa? Secondary questions:

- What are the immediate and long term measures that can be taken to address the current flaws in the SPL legal framework in South Africa?

- How sustainable are the local economic development initiatives introduced by the mining houses in South Africa?

\subsection{Significance of the Study}

Neuman (2003) asserts that social research encompasses efforts to find answers to questions, it has to do with learning something new regarding the social world where a discovery is done through persistence, personal integrity, tolerance for ambiguity, interaction with others and pride in doing quality work. The potential implications and results of this study are expected to bring about positive outcomes in the advancement of local economic development in the local mining communities in South Africa. The main thrust of this research is to establish a roadmap that will bring about changes to the current SLP in order to make it more effective in championing local economic development.

\section{Literature Review}

\subsection{Local Economic Development (LED) and SLPs}

The International Labour Organization (ILO) describes LED as a process that endeavors to facilitate coalitions between stakeholders from both the private and public sector with the agenda to promote development to the local population that comes with creating buy-in from all stakeholders or role players (ILO, 2002). ILO (2002) further asserts that the development strategy should be hinged on the creation of sustainable economic activity through the utilization of local resources and competitive advantage in the global context. World Bank (2000): describes LED as the process by which role players such as the public, business and non-governmental sector collectively work together for the purpose of achieving economic development and employment creation. Thus the main focus is to raise the living standards for all.

Meyer-Stamer (2008) describes LED as the capacity of any given area, locality or region to generate increasing income for the improvement of the quality of life for its residents. Its mandate includes attempts to remove barriers and sanctions that have historically inhibited small to medium enterprise businesses from entering 
the market. Meyer (2013) asserts that LED is a process in which the public, business and non-governmental role players work collectively for the common purpose of creating a better standard of life for local communities through economic empowerment and development.

According to a research carried out by The Centre for Applied Legal Studies (CALS), the economic development which comes with benefits for both the community and workers as encapsulated in the Mining Charter and the Social and Labor Plan (SLP) System is categorically outlined in the mentioned documents which contain direct obligations to contribute meaningfully to the economic and social development of mine-affected communities. The SLP system, in particular, is meant to channel benefts into mine-affected communities to ensure that impacted areas are not left destitute and impoverished by mining (CALS, 2018).

\subsection{SA Context}

\section{LED Programmes: Case Studies}

In South Africa, a series of LED interventions and examples of its practical applicability as a means to improve communities have been rolled out to date. This became a topical issue in an LED Dissemination survey carried out by the European Union and South African government where a study was conducted of pro-poor local economic development in 30 urban and 50 rural municipalities of South Africa. Below are the research results that came with the selected case studies (CWCI, 2006).

(i) The city of Johannesburg is considered as the most important and vibrant economic hub in sub-Saharan Africa. The focus of the municipal policy is overtly pro-growth in nature in the sense that it has drawn a road map that is aimed at creating support structures and measures meant to directly or indirectly champion economic growth in the poorer sections of the community. Among other projects, The Johannesburg Fashion District initiative is an example of a catalytic project which has significantly pro-poor growth implications where some 1000 clothing micro-manufacturers have been supported through the initiative (CWCI, 2006).

(ii) EThekwini is considered as having a long-established track record as far as economic development is concerned. In fact it is recognized as one of the most efficient and effective metropolis in the country in-spite of slow overall industrial growth where sectors such as textile and clothing have been negatively impacted by cheap imports. Rapid rural-urban migration has not helped either as unemployment rate soured. In order to facilitate local economic development, pro-poor and well known projects such as the Warwick Junction project and the Regeneration Fund were launched. Nevertheless, the challenge has been financial resources and only about 15 $20 \%$ of the capital budget is allocated to pro-poor issues and there is a reliance on national government rather than local funds for pro-poor projects (CWCI, 2006).

(iii) Alicedale is a declining former railway town where unemployment levels reached $90 \%+$. A coalition between the public and the private sectors resulted in the establishment of a hotel complex whose immediate economic and social spinoffs was felt through the creation of 500 permanent and temporary jobs implying the potential small towns have if there is a meaningful public-private partnership (CWCI, 2006).

(iv) Situated in the Cedarberg Mountains in the Western Cape Province, Wuppertal is a small mission community whose unemployment rate is around $75-80 \%$ as well as a considerable outmigration for employment. However there has been an improvement following the support of an NGO which enabled the identification of rooibos tea as a niche market product which has been developed as a commercial crop with 170 farmers. This has to a certain extent reduced unemployment rate (CWCI 2006).

\subsection{The Global Perspective}

On a global context, many countries have benefited in their economic growth from huge mineral resources while others on the other hand, have had challenges mainly because of poor administration. In Africa for example, countries such as Botswana and the Congo are both rich in diamonds; however, research has shown that Botswana is a step above many other African countries in terms of democracy, stability and rapid growth of income (Meyer, 2013). Various surveys have established that there is no evidence of the "natural resource curse" whereby resources cause poverty and conflict in the country instead of bringing socio-economic development (Meyer, 2013) The country has endeavored to avoid the trapping of resources endowment such as conflict and corruption given the fact that minerals account for three-quarters of its exports contributing 40 percent of its GDP. This has been accomplished by the use of a three-pronged approach (Maipose, 2008). These include pursuing economic diversification, divesting revenues as well as investing surplus revenues (African Development Bank, 2009).

According to Alekseev \& Conrad (2009), oil and mineral wealth have positively impacted on the income per capita in East Asia and Latin America.

The discovery of coal and access to iron ore resulted in the historically renowned industrial revolutions in England, and the American Great Lakes region (Frankel, 2010). Many other countries have experienced significant turnaround in their economies following the discovery of huge mineral resources and these include Venezuela from the 1920s to the 1970s, Australia since the 1960s, Norway following its oil discoveries of 1969, Chile since the enactment of a new mining code in 1983, Peru since a privatization program in 1992, and Brazil since the 
lifting of restrictions on foreign mining participation in 1995 (Shaffer \& Ziyadov, 2011). Canada, a major net exporter of natural gas and coal is considered the world's second largest oil reserves trailing behind Saudi Arabia. In-spite of this vast resource, Canada has managed to harness these resources for the well-being of both local communities and the nation at large (Kaznacheev, 2013). According to Findlay (2016), this success can be attributed to the robust regulatory environment and implementation process where royalties, taxes, incentives, permits and licensing for oil and natural gas are administered by provincial bodies, while a federal National Energy Board controls and monitors regulation. The Norwegian government carefully adopted a long-term view and did thorough ground work to ensure they do not fall into the resource trap (Torres, 2014). They have enacted that every year, 4 percent of the mining proceeds are syphoned towards public services an approach that saw countries such as Israel, Chile and Colombia adopt similar strategies in a bid to prevent wealth concentration, currency appreciation and mismanagement and corruption by public officials. Being the world's number one producer of copper (Brink, 2012), Chile has avoided the natural resource curse through ensuring a high degree of transparency, mainly through publicizing information on revenues, royalties, taxes, mining export, values and production volumes, and finances by the government (Barma et al, 2012).

\section{Methodology}

\subsection{Research Method}

A qualitative approach was applied as in-depth and comprehensive information was to be sought from the respondents. The method was chosen based on its ability to allow the researcher to collect detailed information while using a very small sample, where the richness of the data compensates for the relative smallness of the sample (Collins, 2003).

Through the practical approach used, the gathered relevant literature regarding fundamental issues which the local communities are encountering in mining regions. A couple of interviews were conducted for an in-depth collection of data for a better understanding of the research questions. Merriam (1998) asserts that the researcher has to reach out to the people, and this entails fieldwork thus this informed the qualitative approach undertaken.

\subsection{Sampling}

According to Babbie and Mouton (2001), a study population is the totality of elements from which a sample is selected. Bless and Higson-Smith (2002) describe a population as the set of elements that the researcher focuses on and to which the obtained results should be generalized. In addition, Polit and Beck (2006) define the population as a summation of individual elements comprised of similar characteristics or traits.

Maree (2007) defines sampling as the process used to select a portion of the population for the study. Qualitative research is generally based on non-probability and for this survey; the purposive sampling was used as the researcher made reference to a particular case (Cohen, Manion and Morrison, 2000).

\subsection{Analytical Framework}

For the purpose of this research, coding was applied for the initial data analysis. This approach entails the creation of specific categories related to segments of a text. Babbie \& Mouton (2001) points out that each of these categories has dimensions, properties and consequences. The thematic coding concept was used in analyzing the primary and secondary data collected. Based on the similar features, concepts and traits, the collected data was organized into categories. The researcher then linked concepts to each other in terms of a sequence as oppositional sets or as sets of similar categories that were intertwined into theoretical statements. According to Babbie and Mouton (2001), coding (in qualitative research) involves two procedures which involve asking questions and making comparisons. They assert that coding begins with taking a segment of a text and labeling based on a meaningful category (a code). Similarities were identified in the responses following data collection.

\section{Key Findings}

\subsection{Undemocratic developmental approach}

The findings basically portray a system in which communities do not have open and free access to SLPs. Programmes are agreed on between the company and the regulator on their behalf and the lack of community voice persists throughout the life-cycle of the SLP. This immensely undemocratic approach to development is not in line with the people centered approach engraved in both international and regional human rights law, including the African Charter on Human and Peoples' Rights (CALS, 2018).

\subsection{No access to SLPs and related information}

Recent research studies have indicated that the majority of community members have never at any given point in time been involved or consulted in the development of SLPs. Discovery was also made of the community members' unawareness how SLPs function and the obligations it has placed upon the mining companies (CALS, 2018). 


\subsection{Weak co-operative governance and responsibility shifting}

Research results showed that ineffective cooperation and communication was established as interviewees noted national departments such as DMR had a tendency of either not consulting in key decisions regarding mining as well as the approval of SLPs, citing reasons of incompetence on the part of local municipalities in conducting effective local economic development planning. Many are times when stakeholders or role players blamed each other instead of acknowledging their share of responsibility in the wake of insignificant change at a community level (CALS, 2018).

\subsection{None regional alignment of SLP initiatives}

The conducted interviews indicated non-alignment and networking between major stakeholders or role players. In order to ensure that local economic development policies are part of a broader, workable and sustainable development plan, the coherence between SLPs and municipal development frameworks is fundamental. Research has shown that there has been grave mistrust between the DMR, local government, mining companies and communities (CALS, 2018).

\subsection{Companies' relationship with traditional leaders}

Allegations have surfaced that dodgy secretive interactions have been happening between traditional leaders and mining companies for the mutual benefit of both parties much to the detriment of communities. This has resulted in unscrupulous secret agreements being concluded between companies and traditional leaders with respect to communal land and on vehicles for administrating the proceeds of mining on that land. Thus, SPL programs end up benefiting the minority traditional leadership while the community at large is languishing in poverty (CALS, 2018).

\subsection{Marginalization of communities directly impacted by mines}

There has not been a clear and concise method of pre-determining the distinct communities that are meant to benefit from SLPs. The present criterion includes municipal demarcations and radius around the mining operations. The current informal selection of community beneficiaries can culminate in the sidelining of communities that are geographically isolated thus excluding them from the benefits thereof (CALS, 2018).

\subsection{Flawed systems for the approval and monitoring of compliance with SLPs}

Research has shown evidence of the shortcomings in the DMR's systems for monitoring compliance with SLPs. Communities alleged that the DMR could not support them during the licensing (and SLP development) process and was not available at a community level in order to assess the situation regarding compliance issues. In its 2015/2016 annual report, the DRM pointed out that it had conducted 270 SLP verification inspections even though they did indicate what the process involved. Mining company respondents confirmed that various officials in the department did not use consistent approaches in evaluating compliance and the effects of non-compliance (CALS, 2018).

\section{Conclusion and Recommendations}

Literature gathered to date has undoubtedly proved that there are fundamental flaws in the SLP system which inhibits it from accomplishing its developmental goals and objectives to the local communities. Thus in order to overcome this hurdle, this report proposed immediate interventions to better the current SLP system as well as possible longer term alternative models designed to address more fundamental shortcomings of the present SLP system. Below is a summary of the immediate interventions that can be put in practice without making major changes to the SLP model. These include:

- Facilitating easy access to information from the DMR under PAIA by communities;

- More clearer legislative provisions concerning transparency of SLPs and annual compliance reports coupled with positive obligations to convey such to communities;

- Recognition of communities as central stakeholders in the enactment of mining laws, regulations and policy.

- Pursuing the Bench Marks Foundation's proposal as a tool to address the challenges faced by mineaffected communities;

- Pursuing the Bench Marks Foundation's proposal for a community capacitation and development fund whose objective is to complement the problem solving service;

- Chanting in a clear and concise manner, the requirements for community involvement in the design and amendment of SLPs;

- Specifying requirements for periodic feedback to communities regarding progress made in SLPs;

- Formally integrating the development of SLPs into the IDP annual review and required community 
participation in this process.

The longer term and more important interventions were classified into two groups:

Firstly, it is of paramount importance to do the amendment of the mining law in order to come up with a more robust framework that addresses the negative social and economic impacts of mining. This would include the amendments to the current SLP model where formal negotiations between communities, organized labor, mining companies and government should be facilitated.

The second intervention would involve the replacement of project-based SLPs by a regional participatory and inclusive structure. This approach is meant to elicit mandates on projects directly from the local communities and is, according to our opinion, the most effective strategy that will see a direct community involvement and interaction with stakeholders. Last but not least, is a recommendation that the government employs an agency that would oversee the implementation of local economic development of mine-affected communities, as per the Mining Charter of 2017.

\section{References}

Bank, W. (2012). Increasing Local Procurement By the Mining Industry in West Africa. World Bank, Washington DC.

Barma, N., Kaiser, K., Le, T. M. \& Viñuela, L. (2012). Rents to Riches. The Political Economy of Natural Resource Led Development. The World Bank, Washington DC.

Binns, T. \& Nel, E. (2003). The Village in a Game Park: Local Response to the Demise of Coal Mining in Kwazulu-Natal, South Africa, Economic Geography, 79:41-66.

CWCI. (2006). Findings on urban and rural pro-poor LED in South Africa. 1-2.

Department of Mineral Resources (DMR). 2010. Guidelines for the submission of a Social and Labour Plan. Pretoria. 85

Donk, M., Swilling, M., Pieterse, E. \& Parnell, S. (Eds.). (2016). Consolidating developmental local government: lessons from the South African experience (pp. 339-356). Cape Town: UCT.

DPLG (Department of Provincial and Local Government). (2002). Draft Local Economic Development Policy, DPLG, Pretoria.

Eggert, R. (2004). Diversification, the Creation of Social Capital and the Promotion of Sustainable Livelihoods: Managing Mineral Wealth, United Nations Commission for Africa (UNECA), www.uneca.org/eca_resources, downloaded 23 August 2007.

GUMALA. Australia: Gumala Enterprises Limited. (2013). Annual Report 2013.

John, L. (2001). Small Business Development,Entrepreneurship and Expanding the Business Sector in a Developing Economy:The Case of South Africa. Johannesburg: University of the Witwatersrand.

Jourdan, P. (2005). The Role of Extractive Industries in Fragile States in Africa, Paper Presented at the African Development Bank Annual Meeting, Tunis, 18 August 2005.86

Jourdan, P \& Mtegha, H. (2005). The NEPAD Spatial Development Program, Paper presented at the African Development Bank, Infrastructure Medium to Long-Term Strategic Framework, Libreville, Gabon, 6 April 2005.

Kaznacheev, P. (2013). „Resource Rents and Economic Growth ${ }^{\text {ee }}$, paper published by the Russian Presidential Academy of National Economy and Public Administration.

Maipose, G. (2008). Policy and Institutional Dynamics in Sustained Growth in Botswana. University of Botswana, Gaborone.

Mavrotas, G., Murshed, S. M. \& Torres, S. (2014). Natural resource dependence and economic performance in the 1970-2000 period. Review of Development Economics, 15(1), 124-138.

Meyer, D.F. (2013). An exploration of solutions for rural development: The case of the northern Free State. NWU: Vaal Campus. Vanderbijlpark (PhD thesis).

Nel, E. \& John, L. (2006). The Evolution of Local Economic Development in South Africa. Urban Forum.

Nel, E. \& Rogerson, C.M. (2005). Pro-poor local economic development in South Africa Cities: Policy and practice. Africa Insight, 35 (2) 5-20.

Powell, D. (2008). Intergovernmental delivery in municipal areas: reflections on current practice.

Otto, J. \& Cordes, J. (2002). The Regulation of Mineral Enterprises: A Global Perspective on Economics, Law and Policy. Rocky Mountain Mineral Law Foundation, Colorado.

Pillay, U., Tomlinson, R. \& J. Du Toit (eds). (2006). Democracy and Delivery, Urban Policy in South Africa, HSRC Press, Pretoria.

Rodriguez-Pose, A. (2008). Milestones and challenges of LED practice and academic research. Development Southern Africa, 5, 22-24.

Rogerson, C.M. (2006). Local economic development in post-apartheid South Africa: A ten-year research review, in V. Padayachee (ed.) The Development Decade? Economic and Social Change in South Africa, 1994- 2004, HSRC Press, Cape Town, 227-253. 
Steyn, T. (2008). Personal Interview with Tracy Steyn: Community Development Project Manager Lonmin Marikana Area, Rustenburg.

Tapela, N. (2008). Mining, Urbanization and Regional Development in Southern Africa: Contextualizing the Spatial and Political Economies of Mining-led Urbanization, Paper Presented to the Conference on Planning and Development Perspectives on Mining Towns in South Africa, North-West University, Potchefstroom, 18 June.

Walker, M. (2006). Promoting the Growth and Development of Economic Linkages Arising from Mineral-Based Activities in South Africa, Sustainable Manufacturing? The Case of South Africa and Ekurhuleni. Juta and Co, Cape Town.

Woolcock, M. (1998). "Social Capital and Economic Development: Toward a Theoretical Synthesis and Policy Framework," Theory and Society 27, April, 151-208.

World Bank (2000). Local Economic Development: Quick Reference. Urban Development Division, The World Bank, Washington DC.

World Bank, 2002: Defining LED. Available at www.worldbank.org/urban/led/defining.html

World Bank-Netherlands Partnership Program. (2005). Evaluating and Disseminating Experiences in Local Economic Development (LED) Local Economic Development as an alternative approach to economic development in Sub-Saharan Africa. World Bank, Washington, DC. 